\title{
Normal pregnancy in primary alveolar hypoventilation treated with nocturnal nasal intermittent positive pressure ventilation
}

\author{
Th. Pieters*, J.J. Amy**, D. Burrini**, G. Aubert+, D.O. Rodenstein*, Ph. Collard*
}

Normal pregnancy in primary alveolar hypoventilation treated with nocturnal nasal intermittent positive pressure ventilation. Th. Pieters, J.J. Amy, D. Burrini, G. Aubert, D.O. Rodenstein, Ph. Collard. @ERS Journals Ltd 1995.

ABSTRACT: Nocturnal nasal intermittent positive pressure ventilation (NIPPV) is increasingly used to treat chronic respiratory failure in a wide variety of conditions (myopathies, Ondine's curse, kyphoscoliosis, etc.) and allows a normal everyday life. Some of these diseases affect women of childbearing age.

We report on a young woman suffering from primary alveolar hypoventilation, who presented with limitation of daytime activities, severe oxygen desaturation during sleep, polycythaemia and pulmonary hypertension. These abnormalities completely reversed after a few months of NIPPV applied through a nasal mask. Whilst under ventilatory assistance during sleep, she had an uneventful pregnancy and delivery of a normal baby.

We suggest that in selected patients requiring NIPPV, pregnancy can be contemplated with a reasonable level of safety both for the mother and the child, provided that adequate mechanical ventilatory assistance during sleep is maintained throughout pregnancy.

Eur Respir J., 1995, 8, 1424-1427.
*Pneumology Unit and +Neurology Unit, Cliniques Universitaires Saint-Luc, Brussels, Belgium. **Dept of Gynecology, Andrology and Obstetrics, Academisch Ziekenhuis, Vrije Universiteit Brussel, Brussels, Belgium.

Correspondence: D.O. Rodenstein

Service de Pneumologie

Cliniques Saint-Luc

Av. Hippocrate 10

B-1200 Bruxelles

Belgique

Keywords: Nasal intermittent positive pressure ventilation

pregnancy

primary alveolar hypoventilation

Received: August 291994

Accepted after revision April 111995
Ondine's curse, or central alveolar hypoventilation, is a rare disorder characterized by an absent or diminished ventilatory response to hypercapnia, hypoxia, or both. The disease becomes patent during early childhood or in young adults. By definition, the lungs are normal and there is no demonstrable abnormality of the central nervous system [1]. Whilst patients are sometimes able to maintain normal arterial blood gas values during daytime, disordered breathing is maximal during sleep and may result in profound hypoxaemia. The condition can be effectively treated with assisted ventilation during sleep.

Pregnancy alters lung function and increases $\mathrm{O}_{2}$ requirements [2]. Any pre-existing limitation in ventilation can be exaggerated by pregnancy to the point of precipitating acute respiratory failure and/or impairing foetal growth [3].

We describe the case of a young woman who developed Ondine's curse at childbearing age, and who had an uneventful pregnancy and delivery whilst under treatment with nocturnal nasal intermittent positive pressure ventilation (NIPPV).

\section{Case report}

A 26 year old Caucasian woman was admitted to hospital in 1988 for further evaluation of polycythaemia. She had never smoked and had an unremarkable medical history until the age of 16 yrs, when she complained of hoarseness. At the age of $20 \mathrm{yrs}$, a first pregnancy was terminated after 4 months because of toxoplasmosis. At the age of $21 \mathrm{yrs}$, she became pregnant again.
At 3 months of pregnancy, haemoglobin level was 12 $\mathrm{g} \cdot \mathrm{dL}^{-1}$. The course of the pregnancy was normal. She was delivered of a normal baby weighing $3,710 \mathrm{~g}$. At the age of $25 \mathrm{yrs}$, a diagnosis of idiopathic left vocal cord palsy was made.

In February 1986, on routine examination, haemoglobin and haematocrit were $15.2 \mathrm{~g} \cdot \mathrm{dL}^{-1}$ and $47 \%$, respectively, and in April $198615.3 \mathrm{~g} \cdot \mathrm{dL}^{-1}$ and 45\%, respectively. In November 1986, the patient was admitted to another hospital for a pneumonia. Arterial blood gases were: arterial carbon dioxide tension $\left(\mathrm{Pa}_{\mathrm{a}}, \mathrm{CO}_{2}\right) 10.8$ $\mathrm{kPa}(81 \mathrm{mmHg})$; arterial oxygen tension $\left(\mathrm{Pa}, \mathrm{O}_{2}\right): 5.3 \mathrm{kPa}$ $(40 \mathrm{mmHg})$; arterial oxygen saturation $\left(\mathrm{Stc}_{\mathrm{tc}} \mathrm{O}_{2}\right) 63 \%$. Haemoglobin was $17 \mathrm{~g} \cdot \mathrm{dL}^{-1}$, haematocrit $50 \%$. The patient was intubated and put on assisted ventilation. After $24 \mathrm{~h}$, she could be extubated. The following days blood gas values returned to normal without oxygen administration. The electrocardiogram showed a right bundle branch block and the echocardiogram signs of pulmonary hypertension with right ventricular dilatation $(32 \mathrm{~mm})$. Systolic pulmonary arterial pressure measured during right heart catheterization was $100 \mathrm{mmHg}$.

In February 1988, arterial blood gas measurement showed: $\mathrm{pH} 7.33 ;{\mathrm{Pa}, \mathrm{CO}_{2}}_{6} 6.4 \mathrm{kPa}(48 \mathrm{mmHg}) ; P \mathrm{a}, \mathrm{O}_{2} 10.5$ $\mathrm{kPa}(79 \mathrm{mmHg})$; base excess (BE) $+2 \mathrm{mEq} \cdot \mathrm{L}^{-1} ; \mathrm{HCO}_{3}$ $24 \mathrm{mEq} \cdot \mathrm{L}^{-1}$. Forced vital capacity (FVC) was $91 \%$ predicted, forced expiratory volume in one second (FEV1) $82 \%$ pred, FEV1/FVC $79 \%$, total lung capacity (TLC) $91 \%$ pred, and transfer factor of the lungs for carbon monoxide (TL,CO) $26 \mathrm{~mL} \cdot \mathrm{min}^{-1} \cdot \mathrm{mmHg}^{-1}$ (corrected for 
a) Without oxygen

Sleep stage $\left(M A \cdot h^{-1} 10\right)$

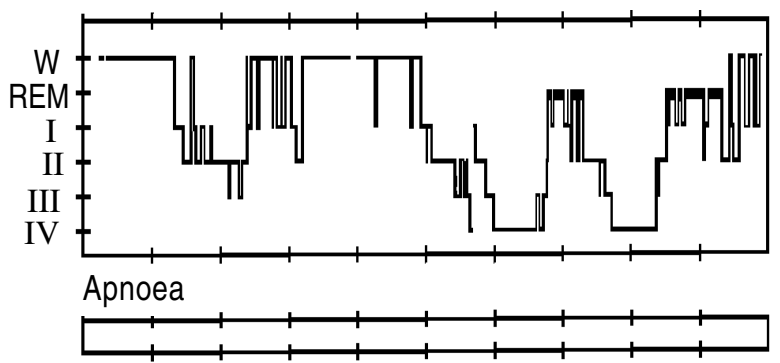

Arterial oxygen saturation \%

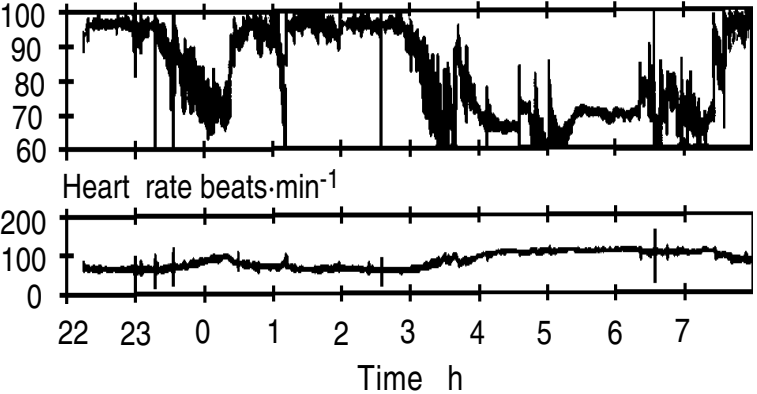

c) NIPPV

BMI $27.3 \mathrm{~kg} \cdot \mathrm{m}^{-2}$ Sleep stage $\left(M A \cdot h^{-1} 13\right)$

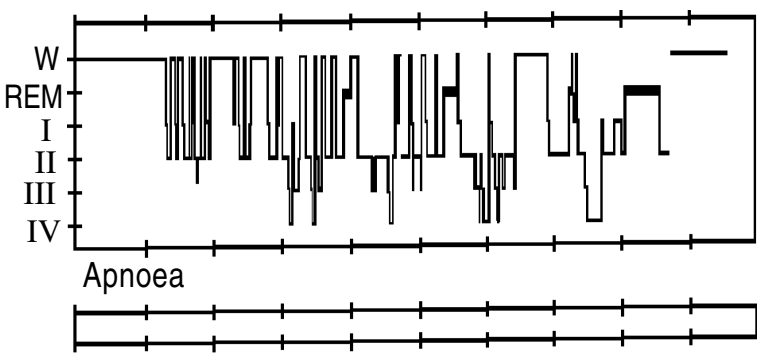

Arterial oxygen saturation \%

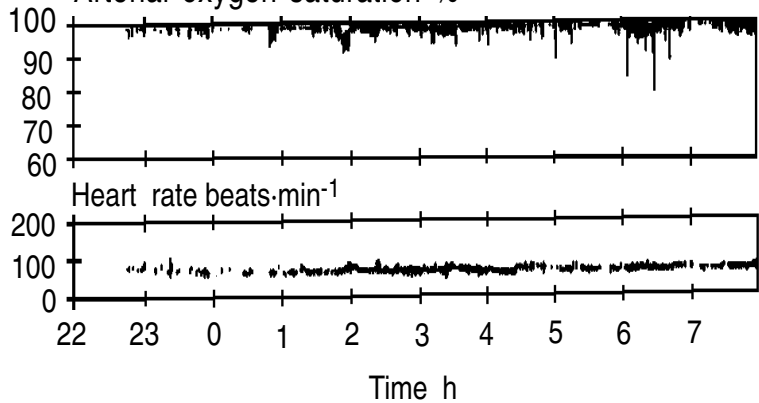

haemoglobin level). The ventilatory response to hypercapnia (Read method) expressed as $\Delta$ minute ventilation $\left(\mathrm{V}^{\prime} \mathrm{E}\right) /$ end-tidal carbon dioxide tension $\left(\Delta \mathrm{PET}, \mathrm{CO}_{2}\right)$ was $0.097 \mathrm{~L} \cdot \mathrm{min}^{-1} \cdot \mathrm{mmHg}^{-1}$ (normal value for women $1.980 \pm 1.129)$

The patient was admitted for additional investigation in March 1988. She had no respiratory complaints. Snoring was infrequent; sleep was agitated; she complained of severe headaches in the morning; there was general weakness but no hypersomnia. Body mass index (BMI) was $25.8 \mathrm{~kg} \cdot \mathrm{m}^{-2}$. Blood pressure was $130 / 80$ $\mathrm{mmHg}$. Cardiopulmonary examination was normal. Haemoglobin was $17.5 \mathrm{~g} \cdot \mathrm{dL}^{-1}$ and haematocrit $50 \%$. Arterial blood gases whilst awake and breathing room b) With oxygen

BMI $25.8 \mathrm{~kg} \cdot \mathrm{m}^{-2}$

Sleep stage $\left(M A \cdot h^{-1} 21\right)$

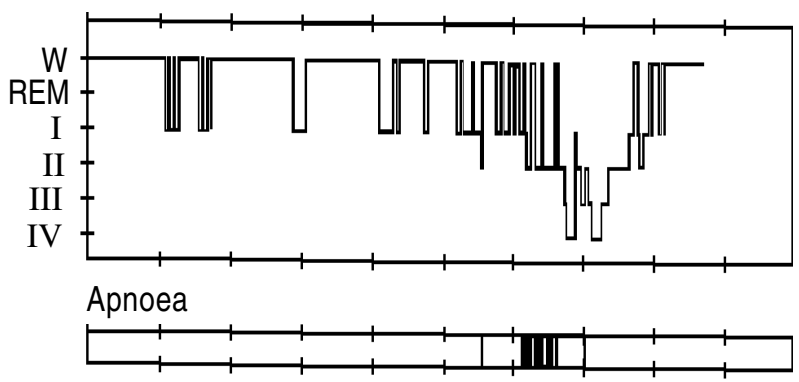

Arterial oxygen saturation \%

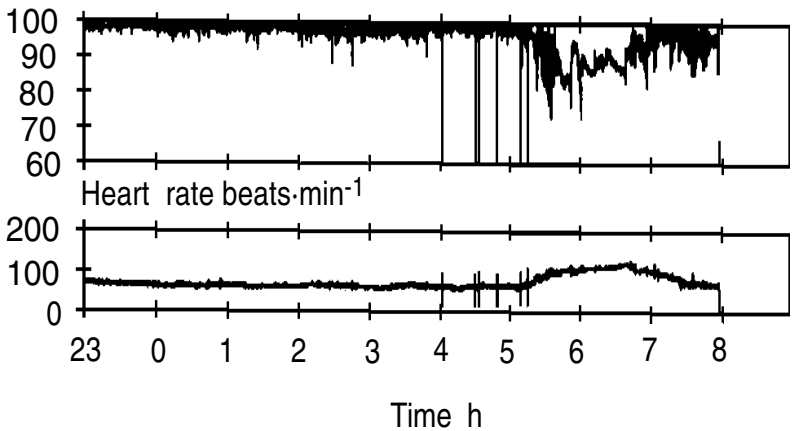

Fig. 1. - Polysomnographic data of the patient. a) without oxygen and b) with oxygen; c) under nasal intermittent positive pressure ventilation (NIPPV). The resolution of each graph is $1 \mathrm{~min}$. Standard hypnogram (W: wakefulness; REM: rapid eye movement sleep; I, II, III and IV: stages 1, 2, 3 and 4 non-REM sleep). Apnoeas; each vertical bar represents $1 \mathrm{~min}$ with apnoeas. Transcutaneous oxygen saturation $\left(\mathrm{Stc}, \mathrm{O}_{2}\right)$; each vertical bar is the mean $\pm \mathrm{SD}$ of the values recorded during each minute. Heart rate; each vertical bar is the mean \pm SD of the values recorded during each minute. a) b) Note the improvement of Stc, $\mathrm{O}_{2}$ under oxygen, but very short sleep time and fragmented sleep with central apnoeas. Stc, $\mathrm{O}_{2}$ decreases in parallel with slow wave sleep. Note also that the pulse rate increases simultaneously with the fall in $\mathrm{Stc}_{\mathrm{t}} \mathrm{O}_{2}$. c) Under NIPPV $\mathrm{Stc}_{\mathrm{t}, \mathrm{O}_{2}}$ is quite normal and pulse rate is stable. BMI: body mass index, MA: movement arousals (per hour of sleep).

air were: $\mathrm{pH} 7.42 ; P \mathrm{a}, \mathrm{CO}_{2} 5.3 \mathrm{kPa}(40 \mathrm{mmHg}) ; P \mathrm{a}, \mathrm{CO}_{2} 9.3$ $\mathrm{kPa}(70 \mathrm{mmHg}) ; \mathrm{Stc}, \mathrm{O}_{2} 94 \% ; \mathrm{BE}+2 \mathrm{mEq} \cdot \mathrm{L}^{-1}$; and increased $\mathrm{HCO}_{3} 26 \mathrm{mEq} \cdot \mathrm{L}^{-1}$. After three vital capacity manoeuvres, $\mathrm{Pa}, \mathrm{O}_{2}$ increased to $14.6 \mathrm{kPa}(110 \mathrm{mmHg}), \mathrm{Stc}_{\mathrm{O}} \mathrm{O}_{2}$ to $98 \%$, and $\mathrm{pH}$ to 7.50 ; and $\mathrm{Pa}_{\mathrm{a}, \mathrm{CO}_{2}}$ declined to $4 \mathrm{kPa}(30$ $\mathrm{mmHg}$ ). Thyroid hormones were normal. The electrocardiogram showed the same conduction defect as before. The pulmonary function tests were normal. A magnetic resonance imaging of the brain was normal.

An overnight polysomnography performed as described previously [4] revealed large falls in transcutaneous $\mathrm{Stc}_{\mathrm{tc}} \mathrm{O}_{2}$ (mean awake $\mathrm{Stc}_{\mathrm{t}, \mathrm{O}_{2}}$ 96\%; $87 \%$ during stage 1 non-rapid eye movement (NREM) sleep; 69\% during stages 3 and 4 NREM sleep; and 66\% during rapid eye movement (REM) sleep, with constant oscillations of about 10-20\%) (fig. 1a). Sleep architecture was normal but sleep 
efficiency was low (64\%). Sleep was stable as assessed by the movement arousal (MA) index (number of MA per hour of sleep; normal upper limit in our laboratory $\left.21 \mathrm{MA} \cdot \mathrm{h}^{-1}\right)$. Heart rhythm increased during sleep from 77 beats $\cdot \mathrm{min}^{-1}(\mathrm{bpm})$ during stage 1 NREM to $104 \mathrm{bpm}$ during stage 4 NREM sleep. Respiration was regular but showed a discrete periodic pattern only during stage 1 NREM sleep. There was no apnoea or detectable reduction in oronasal flow amplitudes, as measured by three thermocouples. There was no snoring or demonstrable decrease of chest wall motion amplitudes as assessed by a single strain gauge.

A second sleep study whilst the patient received oxygen, $1 \mathrm{~L} \cdot \mathrm{min}^{-1}$ through nasal prongs, showed a more disturbed sleep. Saturation falls were less deep but persisted during stage 3 and 4 NREM sleep. Respiration was unstable with central apnoeas ( 8 episodes $\cdot h^{-1}$ of sleep; mean duration $20 \mathrm{~s}$; extremes 10-63 s). Heart rhythm showed persisting tachycardia during sleep, despite lower $\mathrm{Stc}, \mathrm{O}_{2}$ falls. Sleep was more unstable, as assessed by the increase of MA index from $10 \mathrm{MA} \cdot \mathrm{h}^{-1}$ without oxygen to $21 \mathrm{MA} \cdot \mathrm{h}^{-1}$ under oxygen (fig. $1 \mathrm{~b}$ ).

A diagnosis of primary alveolar hypoventilation (Ondine's curse) was made. Nasal intermittent positive pressure ventilation (NIPPV) was proposed. The patient accepted the treatment 8 months later. Haemoglobin was then $19 \mathrm{~g} \cdot \mathrm{dL}^{-1}$; haematocrit $59 \%$; $\mathrm{pH} 7.39 ;{\mathrm{Pa}, \mathrm{O}_{2}}: 9.3 \mathrm{kPa}(70$ $\mathrm{mmHg}) ; P \mathrm{a}_{1} \mathrm{CO}_{2} 6.1 \mathrm{kPa}(46 \mathrm{mmHg}) ; \mathrm{BE}+3 \mathrm{mEq} \cdot \mathrm{L}^{-1}$; and $\mathrm{HCO}_{3} 28 \mathrm{mEq} \cdot \mathrm{L}^{-1}$. After a few days of habituation, another polysomnography during assisted ventilation with a volumetric respirator, set at a tidal volume of $0.8 \mathrm{~L}$, a frequency of 20 cycles $\mathrm{min}^{-1}$ and inspiratory/expiratory ratio $1 / 1$, showed a stable heart rhythm and $\mathrm{Stc}, \mathrm{O}_{2}$ with no apnoeas (fig. 1c). Sleep efficiency remained low $(61 \%)$ but all sleep stages were present, with a normal distribution. Sleep was stable with $13 \mathrm{MA} \cdot \mathrm{h}^{-1}$ of sleep.

Home treatment with nocturnal NIPPV was started. Subsequently, the patient's headaches vanished and her general condition improved spectacularly. The electrocardiogram returned to normal. A control Doppler echocardiography showed the disappearance of signs of pulmonary hypertension. Ventilatory response to $\mathrm{CO}_{2}$ gave the same value as one year previously. Haemoglobin spontaneously decreased to $11.3 \mathrm{~g} \cdot \mathrm{dL}^{-1}$ and haematocrit to $33 \%$. A fourth polysomnography was carried out under NIPPV after 6 months of therapy. There was no abnormality.

Two years after the institution of NIPPV treatment, the patient became pregnant for the third time. Regular domiciliary monitoring with pulse oximetry, both before and during pregnancy, confirmed adequate night oxygenation, with $\mathrm{Stc}_{\mathrm{tc}} \mathrm{O}_{2}$ at $95 \%$ or higher. No change of the respirator parameters was necessary during pregnancy. The clinical status remained normal; and the foetus showed a normal growth pattern. Labour was induced at 39 weeks. The first stage of labour was eucinetic and the foetal heart rate monitoring was normal throughout. The second stage lasted $1 \mathrm{~h}$ because of persistency of a posterior occiput position, with deflection of the foetal head. A vacuum extraction was performed. The baby weighed $3,740 \mathrm{~g}$ for a length of $51.5 \mathrm{~cm}$. The Apgar scores were 9,10 and 10 at 1,5 and $10 \mathrm{~min}$ of life, respectively. The placenta weighed $590 \mathrm{~g}$. The umbilical venous blood $\mathrm{pH}$ was $7.26, \mathrm{~Pa}_{\mathrm{a}} \mathrm{O}_{2} 5.2 \mathrm{kPa}(39 \mathrm{mmHg})$ and $P \mathrm{a}, \mathrm{CO}_{2} 4.5 \mathrm{kPa}(34 \mathrm{mmHg})$. The foetal haemoglobin was $15.3 \mathrm{~g} \cdot \mathrm{dL}^{-1}$ with a haematocrit of $48.8 \%$. All of these values are normal.

Twenty seven months later the patient (who is still under NIPPV therapy) and her baby are in good health.

\section{Discussion}

To the best of our knowledge, this is the first case report of a normal pregnancy and labour in a woman with primary alveolar hypoventilation treated with NIPPV.

First described in 1962 by Severinghaus and Mitchell [5] under the term Ondine's curse, primary alveolar hypoventilation remains a rare disease. Whereas it may remain in the latent state, abrupt respiratory failure may occur following airway infections, as described in infants [6]. Therapy rests on the control of breathing during sleep. Electrophrenic pacing has been used in some patients but can lead to upper airway occlusion [7], so that positive pressure ventilation is preferred.

Our patient had several features consistent with the diagnosis of primary alveolar hypoventilation: pulmonary function was normal; $\mathrm{Pa}, \mathrm{CO}_{2}$ was extremely variable within very short periods of time; there was practically no response whatsoever to hypercapnia by the rebreathing method; there was no sign of upper airway obstruction during sleep (neither snoring nor sleep fragmentation); and the periodic breathing pattern was confined to stage 1 NREM sleep. In addition, there were no clinical signs of muscle weakness, either respiratory or general. Although we did not test her response to hypoxia, and nocturnal increase in $\mathrm{Pa}_{\mathrm{a}} \mathrm{CO}_{2}$ was not documented, we believe that no other diagnostic category can better be applied to this patient. Moreover, the complete reversibility of her pulmonary artery hypertension under therapy also suggests the same diagnosis. Therapy rests on assisted ventilation. Oxygen is not considered as an effective treatment, since it will only reduce the falls in $\mathrm{Sa}_{\mathrm{a}} \mathrm{O}_{2}$, but it will not modify (and may even aggravate) hypercapnia [8]. In our patients, oxygen administration increased sleep fragmentation and heart rhythm, and resulted in the appearance of central apnoeas (fig. 1b).

The condition underlying the ventilatory failure may be stable or only slowly progressive and patients can be affected during reproductive life. As stability and better performance are achieved, patients may want to fulfil their social, professional and emotional needs, including pregnancy.

When evaluating the safety of pregnancy in women with respiratory failure one should not only assess the respiratory function when the patient is awake, but also the adequacy of respiration during sleep [9]. Indeed, further alteration in breathing pattern and in control of ventilation is prone to take place during sleep, particularly during REM sleep periods; this is because during sleep the normal reduction in tone of muscles, in 
respiratory drive and in chemoresponses superimpose on the altered mechanics or reduced respiratory drive. For instance, primary alveolar hypoventilation usually induces few changes in arterial blood gases during wakefulness; most abnormalities are confined to sleep periods. The decrease in ventilation observed during sleep leads to severe hypoxaemia and hypercapnia, with secondary polycythaemia and pulmonary hypertension [8].

Most of the changes in respiratory physiology in normal pregnant women derive from two mechanisms: the elevation of the diaphragm secondary to the enlarging uterus and the increase in progesterone levels [2]. The former causes a marked decrease in functional residual capacity [10], and in the oxygen reserve within the lung, so that falls in $\mathrm{Stc}, \mathrm{O}_{2}$ during apnoeas or hypopnoeas may by more profound than usual. On the other hand, the elevation of the diaphragm puts it at a more advantageous position with respect to the length/tension relationship [11]. High progesterone levels result in hyperventilation with increases in tidal volume, whereas respiratory frequency hardly changes. This results in a substantial decrease of $\mathrm{Pa}_{\mathrm{a}} \mathrm{CO}_{2}$ whilst $\mathrm{Pa}, \mathrm{O}_{2}$ is only marginally reduced, although more so in the supine position [12]. Finally, it has been shown that airway conductance increases in pregnancy [13].

Pulmonary hypertension, whatever its aetiology, carries a grave prognosis during pregnancy [14]. Because pulmonary hypertension and hypercapnia were no longer present in our patient after a few months of NIPPV, pregnancy was not discouraged.

As far as we know, there are no reports on pregnancy and foetal fate in Ondine's curse or in patients necessitating long-term assisted ventilation during sleep. However, several papers describe the evolution of pregnancy in patients with obstructive sleep apnoea syndrome (OSAS). The latter shares in common with Ondine's curse the presence of repetitive falls in $\mathrm{Stc}_{\mathrm{t}} \mathrm{O}_{2}$, although the mechanism is completely different. OSAS can result in foetal growth retardation $[15,16]$. Foetal heart rate changes were observed but there was no clear relation with the apnoeic episodes [16]. Although foetal tissues have been assumed to be more resistant to hypoxia than adult tissues [17], there is evidence that even a small degree of hypoxaemia can be detrimental to the foetus [18]. Presumably, in the case discussed here, foetal development might have been impaired, had NIPPV not been used. It is worth mentioning that this patient was probably healthy during the first two pregnancies, as suggested by normal haemoglobin levels both during and after the second pregnancy. Full-blown Ondine's curse appears to have become clinically evident for the first time during the 1986 admission.

Since patients with Ondine's curse are able to ensure adequate blood gas values during wakefulness, we felt it useless to assist the patient with NIPPV during delivery. Nevertheless, her respirator was at hand, and the medical team was prepared to use it if necessary.

In conclusion, we have presented the case of a young woman with Ondine's curse, in whom therapy with NIPPV allowed a normal pregnancy and delivery of a healthy baby.
Acknowledgements: The authors thank M. Boulengier and $\mathrm{C}$. Bragagnini for secretarial assistance.

\section{References}

1. Shneerson J. Disorders of autonomic control of respiration. In: Shneerson J, ed. Disorders of Ventilation. Oxford, Blackwell Scientific Publications, 1988: pp. 118127.

2. Pernoll ML, Metcalfe J, Kovach A, Wachtel R, Dunham MJ. Ventilation during rest and exercise in pregnancy and postpartum. Respir Physiol 1975; 25: 295-310.

3. Sawicka EH, Spencer GT, Branthwaite MA. Management of respiratory failure complicating pregnancy in severe kyphoscoliosis: a new use for an old technique? Br J Dis Chest 1986; 80: 191-196.

4. Delguste P, Aubert-Tulkens G, Rodenstein DO. Upper airway obstruction during nasal intermittent positive pressure hyperventilation in sleep. Lancet 1991; 338: 12951297.

5. Severinghaus JW, Mitchell RA. Ondine's curse: failure of respiratory center automaticity while awake, (abstract). Clin Res 1962; 10: 122.

6. Guilleminault C, McQuitty J, Ariagno RL, Challamel M, Korobkin R, McClead RE. Congenital central alveolar hypoventilation syndrome in six infants. Pediatrics 1982; 70: 684-694.

7. Hyland RH, Hutcheon MA, Perl A, et al. Upper airway occlusion induced by diaphragm pacing for primary alveolar hypoventilation: implications for the pathogenesis of obstructive sleep apnoea. Am Rev Respir Dis 1981; 124: $180-185$.

8. Bubis MJ, Anthonissen NR. Primary alveolar hypoventilation treated by nocturnal administration of $\mathrm{O}_{2}$. Am Rev Respir Dis 1978; 118: 947-953.

9. King TE. Restrictive lung disease in pregnancy. In: Niederman MS, ed. Clinics in Chest Medicine. Philadelphia, Saunders, 1992; 13: pp. 607-622.

10. Elkus R, Popvich J. Respiratory Physiology in Pregnancy. In: Niederman MS, ed. Clinics in Chest Medicine. Philadelphia, Saunders, 1992; 13: pp. 555-565.

11. Contreras G, Guttierez M, Beroiza T, et al. Ventilatory drive and respiratory muscle function in pregnancy. $A m$ Rev Respir Dis 1991; 144: 837-841.

12. Noble PW, Lavee AE, Jacobs MM. Respiratory diseases in pregnancy. Obstet Gynecol Clin North Am 1988; 15: 391-428.

13. Gee J, Packer B, Millen J, Robin E. Pulmonary mechanics during pregnancy. J Clin Invest 1967; 46: 945-952.

14. Perloff J. Pregnancy and cardiovascular disease. In: Braunwale E, ed. Heart Disease. Philadelphia, Saunders, 1988; pp. 1848-1869.

15. Schoenfeld A, Ovadia, Neri A, Freedman S. Obstructive Sleep Apnoea (OSA): implications in maternal-fetal medicine. A hypothesis. Med Hypotheses 1989; 30: $51-54$.

16. Charbonneau M, Falcone T, Cosio MG, Levy RD. Obstructive sleep apnea during pregnancy: therapy and implications for fetal health. Am Rev Respir Dis 1991; 144: 461-463.

17. Boyle R. New pneumatical experiments about respiration. Philos Trans R Soc Lond 1670; 5: 2011-2031.

18. Longo LD. Respiratory gas exchange in the placenta. In: Fishman AP, ed. Handbook of Physiology. Section 3. The Respiratory System. Bethesda, American Physiological Society, 1987 (4); pp. 351-401. 